\title{
Infección y enfermedad por Rickettsia spp. del grupo de las fiebres manchadas en pacientes febriles del Urabá antioqueño, Colombia
}

\author{
Erica Johana Gil-Lora', Jessica Julieth Patiño-Gallego', Leidy Yoana Acevedo-Gutiérrez², Carolina Montoya-Ruizz', \\ Juan David Rodas-González ${ }^{4}$
}

\section{RESUMEN}

Objetivo: determinar la frecuencia de la infección y enfermedad por Rickettsia spp. del grupo de las fiebres manchadas en pacientes febriles del Urabá antioqueño, que asistieron a centros hospitalarios de la región.

Métodos: se incluyeron en el estudio pacientes febriles provenientes de 9 instituciones de salud de la región del Urabá, los cuales fueron encuestados para determinar sus variables clínicas y demográficas. De estos pacientes se obtuvieron muestras de suero durante las fases aguda y convaleciente de la enfermedad. Para cada muestra se determinó la seropositividad (título $\geq 64$ ) y su título de anticuerpos seriados dobles mediante inmunofluorescencia indirecta para IgG contra el antígeno de Rickettsia rickettsii.

Resultados: se analizaron 89 pacientes febriles con 89 muestras de fase aguda y 60 en fase convaleciente. Los síntomas más comunes de los pacientes fueron cefalea, ictericia, mialogias, náuseas, dolor abdominal, trombocitopenia y vómito. El 55,1 \% de los pacientes provenía de áreas rurales. Se obtuvo seropositividad del 40,4 \% con títulos entre 64-512, infección previa en un $33,7 \%$ y rickettsiosis en 6 pacientes $(6,7 \%)$. Los pacientes con seroconversión o serorefuerzo provenían de los municipios de Apartadó ( $n=2)$, Chigorodó $(n=1)$, Necoclí $(n=2)$ y Turbo ( $\mathrm{n}=1$ ); el hallazó clínico más destacado fue la trombocitopenia.

1 Estudiante de Pregrado Microbiología y Bioanálisis, Universidad de Antioquia, Medellín, Colombia.

2 Microbióloga y Bioanalista, Mágister en Ciencias Básicas Biomédicas, Grupo de Investigación en Ciencias Veterinarias, Centauro, Universidad de Antioquia, Medellín, Colombia. Ingeniera Biológica, Mágister y PhD en Ciencias Básicas Biomédicas, Grupo de Investigación en Ciencias Veterinarias, Centauro, Universidad de Antioquia, Medellín, Colombia.

4 Médico Veterinario, Mágister en Ciencias Básicas Biomédicas PhD en Ciencias veterinarias, Grupo de Investigación en Ciencias Veterinarias, Centauro, Universidad de Antioquia Medellín, Colombia.

Correspondencia: Erica Johana Gil-Lora; erikajohana0306@hotmail.com

Recibido: julio 18 de 2018

Aceptado: enero 13 de 2019

Cómo citar: Gil-Lora EJ, Patino-Gallego JJ, Acevedo-Gutierrez LY, Montoya-Ruiz C, Rodas-Gonzalez JD. Infeccion y enfermedad por Rickettsia spp. del grupo de las fiebres manchadas en pacientes febriles del Uraba antioqueno, Colombia. latreia. 2019 Jul-Sep;32(3):167-176. DOI. 10.17533/udea.iatreia.15. 
Conclusiones: se demostró que la infección y la enfermedad rickettsial continúan siendo activas en la zona del Urabá. Este hallazgo permite alertar a las autoridades de salud de la región para que se brinde tratamiento con antibióticos a los casos sospechosos de manera temprana y de esta forma evitar las muertes o secuelas derivadas de este tipo de infecciones.

\section{PALABRAS CLAVE}

Ácaros y Garrapatas; Fiebre de Origen Desconocido; Técnica del Anticuerpo Fluorescente Indirecta; Rickettsiosis; Zoonosis

\section{SUMMARY}

Rickettsia spp. infection of the group of spotted fevers in febrile patients of the Urabá Antioquia, Colombia

Objective: Determine the frequency of infection and disease by Rickettsia spp. of the spotted fever group in febrile patients from Urabá Antioquia attended by hospital centers of the region.

Methods: Patients from nine health institutions of the Urabá region were included in the study. These patients received a survey with questions about their clinical and socio-demographic variables. Eighty-nine acutephase serum samples, and 60 convalescent serum samples, were obtained from these patients, and each sample was tested (IgG) by Indirect Immunofluoerscence Assay (IIFA) using a dilution of 1:64 against $R$. rickettsii. Furtherly, positive sera were tittered by two-fold serial dilutions using the same antigen.

Results: Patients showed symptoms such as fever, headache, jaundice, myalgias, nausea, abdominal pain, petechiae, thrombocytopenia and vomiting. Most of these patients came from rural areas $(55,1 \%)$. Seropositivity was obtained in $40,4 \%$ patients with titers between $64-512$, a $33,7 \%$ with previous infection and the disease was found in 6 patients $(6,7 \%)$. Patients with seroconversion, or a fourlfold rise antibody titer between acute and convalescent samples, came from the municipalities of Apartadó $(n=2)$, Chigorodó $(\mathrm{n}=1)$, Necoclí $(\mathrm{n}=2)$ and Turbo $(\mathrm{n}=1)$, and the most relevant clinical finding was thrombocytopenia in four of the patients.

Conclusions: This study demonstrated that infection and rickettsial disease continues being active in the Urabá region. This situation represents a warning for the health authorities of the region and suggests them to provide appropriate treatment to avoid deaths or sequelae derived from this type of infections.

\section{KEY WORDS}

Acari; Fever of Unknown Origin; Fluorescent Antibody Technique, Indirect; Rickettsiaceae Infections; Zoonoses

\section{INTRODUCCIÓN}

Las rickettsiosis son enfermedades febriles y zoonóticas causadas por bacterias del género Rickettsia, transmitidas por artrópodos tales como las garrapatas, pulgas y los piojos, entre otros. El género Rickettsia se clasifica según características serológicas y moleculares en los grupos tifo, ancestral, transicional y el de Fiebres Manchadas (GFM). EI GFM está conformado por más de 20 especies, se distribuye en todos los continentes y puede contener especies patógenas para los humanos. Estas causan enfermedades de importancia considerable como la fiebre botonosa mediterránea, originada por Rickettsia conorii, endémica en la cuenca mediterránea (sur de Europa, sur y este de África, India y Oriente Medio) donde pueden presentar mortalidades del $21 \%$ (1-3).

En América las especies Rickettsia rickettsii y Rickettsia parkeri son de importancia en salud pública, especialmente $R$. rickettsii, por ser la más virulenta del GFM; es transmitida principalmente por garrapatas duras de los géneros Amblyomma spp., Rhipicephalus spp., y Dermacentor spp. (4). R. rickettsii es el agente etiológico de la Fiebre manchada de las Montañas Rocosas (FMMR), enfermedad que se ha reportado en varios países de América (Estados Unidos, México, Costa Rica, Panamá, Colombia, Brasil y Argentina) (5). La FMMR presenta porcentajes de letalidad variables, entre $2,9 \%$ y $28,4 \%$ para México y Brasil, así como del 
0,5\% para Estados Unidos; estos valores pueden ser explicados por las discrepancias en los distintos programas de vigilancia existentes, el tratamiento oportuno y las diferencias en las cepas bacterianas, entre otras causas (6).

La FMMR en humanos tiene un período de incubación de 10 a 14 días. Posteriormente, aparecen síntomas como fiebre, usualmente mayor a $39,5^{\circ} \mathrm{C}$, dolor de cabeza, mialogia generalizada, problemas digestivos como náuseas, vómito, diarrea, anorexia, escalofríos y, en algunos casos, exantema. Estos sionos y síntomas no son patognomónicos de la enfermedad y suelen estar presentes en otras patologías, con las cuales se debe hacer diagnóstico diferencial, tales como la malaria, leptospirosis y el dengue, entre otras (7).

En Colombia se describió por primera vez un brote de FMMR en 1937 por el doctor Luis Patiño Camargo, en el municipio de Tobia (Cundinamarca), que presentó una letalidad del $95 \%$ (8). Posteriormente, se ha visto como una enfermedad que reemergió con varios brotes, con letalidades entre el $27 \%$ y $54 \%$ en los municipios de Necoclí (Antioquia, 2006), Los Córdobas (Córdoba, 2007), y Turbo (Antioquia, 2007-2008) (9-11). Además, se ha evidenciado el contacto de la población con la bacteria gracias a estudios serológicos y reportes de casos (12-15).

Pese a que en la región del Urabá antioqueño previamente se reportó la infección y la enfermedad en los municipios de Necoclí y Turbo $(9,11)$, aún hoy, el panorama epidemiológico y clínico no es claro. Este comportamiento se explica, en parte, por el poco estudio de los pacientes febriles y el enmascaramiento de los síntomas y sionos con otras enfermedades con curso similar (dengue, malaria, entre otras), lo cual constituye un riesgo cuando los pacientes no reciben el tratamiento oportuno (16).

En relación a lo anterior, este trabajo tuvo como objetivo determinar la frecuencia de infección y enfermedad por Rickettsia spp. del GFM en pacientes febriles deI Urabá antioqueño, que asistieron a centros hospitalarios de la región, con el fin de contribuir al conocimiento de la rickettsiosis, así como al diagnóstico diferencial de los síndromes febriles indiferenciados, que alerte a las autoridades de salud de la región para establecer medidas de prevención y control, sumado al suministro de un tratamiento adecuado y oportuno que ayude a evitar las pérdidas humanas y las posibles complicaciones o secuelas.

\section{METODOLOGÍA}

\section{Tipo de estudio y participantes}

Se realizó un estudio descriptivo con un muestreo por conveniencia de casos incidentes en pacientes con la aparición de una enfermedad febril (temperatura oral mayor o igual a $38^{\circ} \mathrm{C}$, de menos de cuatro días de evolución y con residencia mayor a 10 días en la zona) de origen desconocido (16). Dichos pacientes asistieron a los centros de salud del Urabá antioqueño: Clínica Chinita, Clínica Urabá, Hospital de Necoclí, Hospital de Turbo, Hospital de Apartadó, Clínica Urabá, Serviucis, Clínica Central e IPS Universitaria entre junio de 2013 y noviembre de 2014; en el marco del macroproyecto titulado Aislamiento, caracterización y análisis epidemiolóoico de un Hantavirus detectado en Necoclí, CoIombia (código Colciencias: 111554531578). Se tomó por punción venosa una muestra de sangre a los pacientes en fase aguda (el día de visita al centro médico), y otra durante la fase convaleciente de la enfermedad (aproximadamente dos semanas después).

Se incluyeron pacientes procedentes de áreas rurales y urbanas de Urabá, a quienes se les diligenció un consentimiento informado y una encuesta en el sitio de la consulta. Esta encuesta recogió información sobre variables clínicas y socioepidemiológicas. Se definieron como criterios de exclusión: individuos con muestra de suero pero sin historia clínica o viceversa, que tuvieran diagnóstico de otra enfermedad o que decidieran voluntariamente no participar (autoexclusión). Se incluyeron pacientes negativos por gota gruesa para malaria y que asistieron a los centros médicos de la zona.

\section{Aspectos éticos}

Los procedimientos realizados en el presente estudio fueron avalados por el Comité de Bioética de la Universidad de Antioquia mediante el acta n. ${ }^{\circ} 017$ del 14 de septiembre de 2017; los datos obtenidos se consolidaron en una base de datos anónima.

\section{Inmunofluorescencia indirecta (IFI)}

Se procesaron muestras de suero para la determinación de anticuerpos IogG contra Rickettsia spp. del GFM 
mediante la técnica de IFI (17-19), descrita por Londoño et al. 2017. Se utilizaron placas sensibilizadas con antígenos crudos de un aislamiento de $R$. rickettsii, cepa Uramita (cepa aislada y caracterizada en el grupo de investigación Centauro). En cada placa se incluyeron sueros de control positivo y negativo, se adicionaron $10 \mu \mathrm{L}$ del conjugado (Anti-human IgG marcado con Isotiocianato de Fluoresceína, FITC). Anticuerpo producido en cabra (SIGMA 038K4846), usado a una dilución de 1:3200 en diluyente de muestra (20).

La lectura se realizó en un microscopio de fluorescencia (Nikon EFD-3 ${ }^{\circledR}$ ) con un objetivo $100 \mathrm{X}$ y 450 a 500 $\mathrm{nm}$ de longitud de onda. Las muestras se consideraron como positivas o negativas mediante la comparación con los controles. Se consideraron positivas las muestras con reactividad en la dilución 1:64 o mayor, y se realizaron diluciones seriadas dobles de las muestras hasta encontrar su título final. Se establecieron como enfermos aquellos casos donde se presentó seroconversión o serorefuerzo (aquellas que presentaron un alza cuádruple de anticuerpos en la muestra de la fase convaleciente con respecto a los títulos de la fase aguda), e infectados aquellos seropositivos que no hicieron seroconversión o serorefuerzo $(21,22)$.

\section{Análisis estadísticos}

Se realizó un análisis descriptivo con las variables sociodemográficas, siognos y síntomas de los participantes infectados y enfermos. Los resultados obtenidos se analizaron mediante el software de análisis estadístico SPSS (Statistical Package for the Social Sciences, vers. 24), licenciado por la Universidad de Antioquia.

\section{RESULTADOS}

\section{Características sociodemográficas y clínicas de los participantes}

De los 89 pacientes febriles que ingresaron al estudio, el $66,3 \%$ eran hombres, y la edad media de la población estudiada fue de 32,3 años (edad mínima de 9 y máxima de 80 años). Los pacientes residían en diferentes municipios de la región del Urabá, siendo 22 de ellos de Necoclí (24,7\%), 30 de Turbo (33,7\%), 34 de Apartadó (38,2 \%) y 1 paciente por cada uno de los municipios de Chigorodó $(1,1 \%)$, Carepa $(1,1 \%$ y el corregimiento de Belén de Bajirá $(1,1 \%)$ (Figura 1).

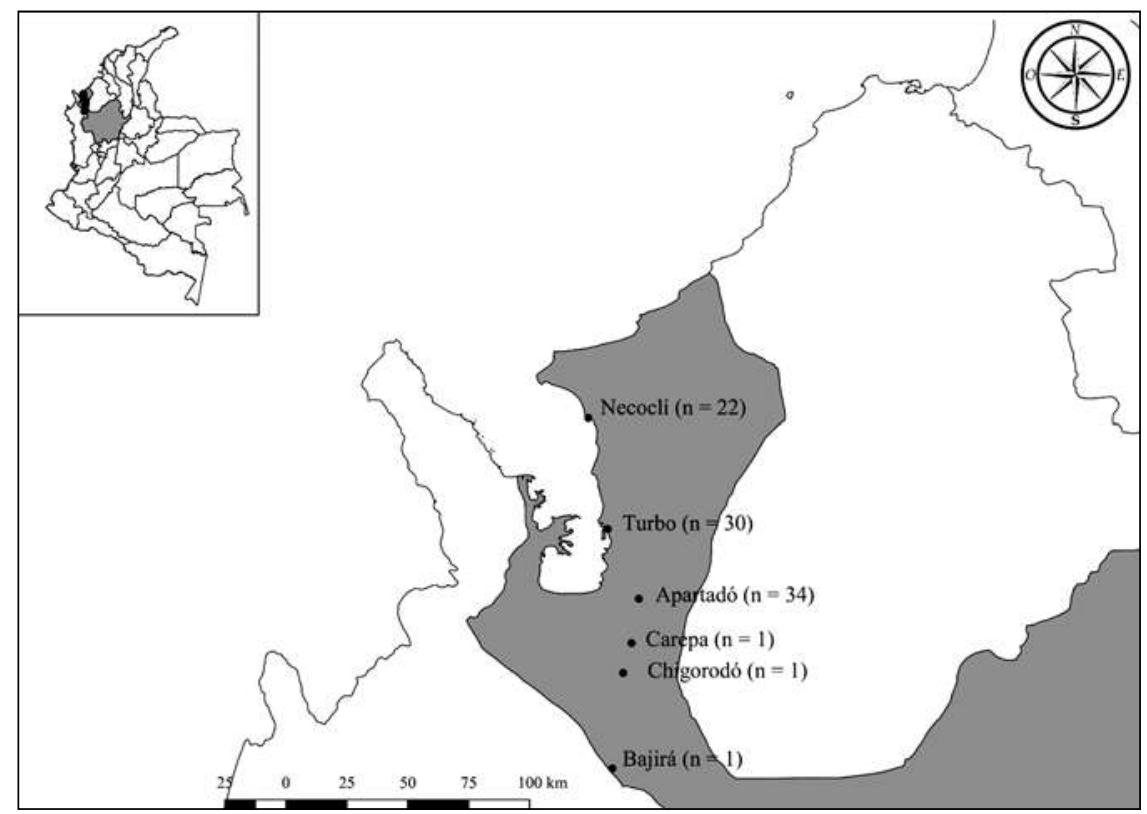

Figura 1. Distribución de los pacientes según el municipio de origen 
Se encontró que los pacientes provenían, en mayor proporción, de zonas rurales (55,7\%). Adicionalmente, un 77,9 \% tenían como ocupación actividades en interiores como ama de casa, estudiante, comerciante, estilista, auxiliar de enfermería y electricista, entre otros. Un $22,1 \%$ en exteriores, entre las que se encontraban labores de agricultor, bananero, palero en el río y militar. El 58,4 \% de la población indicó que al momento de la encuesta convivían con animales domésticos en la casa, y el 73,3 \% reportó haber tenido contacto con ectoparásitos. Sin embargo, en la encuesta no se discriminaron las especies de estos.

Las condiciones higiénico-sanitarias para la mayoría de los pacientes eran deficientes, dado que el 56,3\% no poseía acueducto ni alcantarillado, el 79,3\% no contaba con agua potable y el $49,4 \%$ no tenía servicio de recolección de basuras (Tabla 1).

Tabla 1. Descripción de las características sociodemográficas de los participantes

\begin{tabular}{|c|c|c|c|}
\hline \multicolumn{2}{|c|}{ Variable } & $n=89 *$ & $\%$ \\
\hline \multirow[b]{3}{*}{ Edad (años) } & Femenino & 30 & 33,7 \\
\hline & Masculino & 59 & 66,3 \\
\hline & Media \pm DE & 32 & 18,6 \\
\hline \multirow{4}{*}{ Grupos de Edad (años) } & 0 a 14 & 11 & 12,4 \\
\hline & 15 a 26 & 36 & 40,4 \\
\hline & 27 a 59 & 31 & 34,8 \\
\hline & $>60$ & 11 & 12,4 \\
\hline \multirow{6}{*}{ Municipio de origen } & Apartadó & 34 & 38,2 \\
\hline & Bajirá & 1 & 1,1 \\
\hline & Carepa & 1 & 1,1 \\
\hline & Chigorodó & 1 & 1,1 \\
\hline & Necoclí & 22 & 24,7 \\
\hline & Turbo & 30 & 33,7 \\
\hline \multirow{2}{*}{ Zona } & Urbana & 39 & 44,3 \\
\hline & Rural & 49 & 55,7 \\
\hline \multirow{2}{*}{ Ocupación } & En interiores & 67 & 77,9 \\
\hline & En exteriores & 19 & 22,1 \\
\hline \multirow{2}{*}{ Animales domésticos } & Sí & 52 & 58,4 \\
\hline & No & 35 & 39,3 \\
\hline \multirow{2}{*}{ Contacto con ectoparásitos } & Sí & 63 & 73,3 \\
\hline & No & 23 & 26,7 \\
\hline \multirow{2}{*}{ Agua potable } & Sí & 18 & 20,7 \\
\hline & No & 69 & 79,3 \\
\hline \multirow{2}{*}{ Recolección de basura } & Sí & 44 & 50,6 \\
\hline & No & 43 & 49,4 \\
\hline \multirow{2}{*}{ Acueducto y alcantarillado } & Sí & 38 & 43,7 \\
\hline & No & 49 & 56,3 \\
\hline
\end{tabular}

*Hubo pérdida de datos

En cuanto a los signos y síntomas más frecuentes presentados por los pacientes se encontraron la fiebre, cefalea, ictericia, mialggias, náuseas, dolor abdominal, petequias, trombocitopenia y vómito (Figura 2).

\section{Resultados serológicos}

Se procesaron 149 muestras de suero de los 89 pacientes reclutados, de las cuales 89 correspondieron a la fase aguda y 60 a la fase convaleciente. Un $40,4 \%$ 


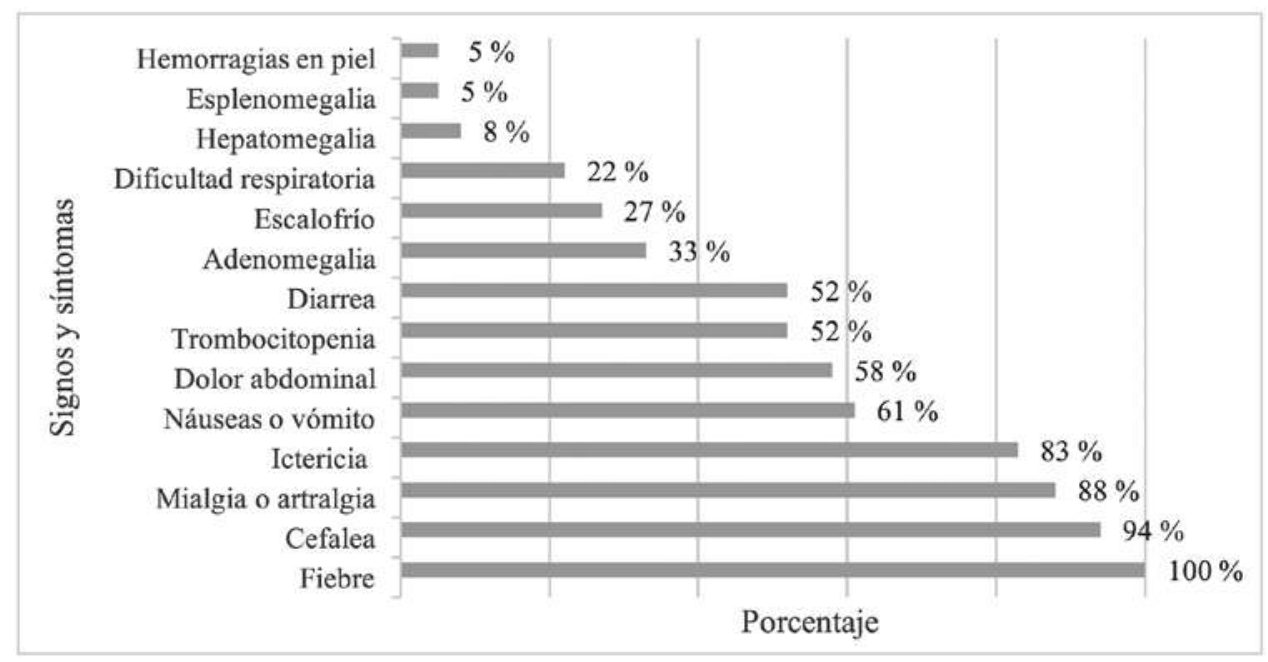

Figura 2. Porcentaje según los síntomas y signos de los participantes

(36/89 pacientes) fueron seropositivos, por lo menos, en una de las dos muestras con títulos de IgG entre 64 y 512. De esos pacientes, 30 no presentaron alza cuádruple entre las muestras, lo cual indicó que un $33,7 \%$ tuvieron una infección previa al episodio febril.

De las personas seropositivas, se encontró que la mayoría fueron hombres (70,0 \%). EI rango de edad estuvo entre 15-77 años y la mediana fue de 28,5 años. En cuanto a la ocupación, el 70,0 \% de los pacientes positivos realizaban sus actividades en interiores, principalmente amas de casa. Para el municipio de origen se observó que, de 30 seropositivos, 33,3\% (10/30) provenían de Apartadó, 33,3 \% (10/30) de Necoclí y $33,3 \%$ (10/30) de Turbo. Un alto porcentaje de los participantes reportaban tener animales domésticos (perros, aves, equinos, entre otros) $(63,3 \%$ y presencia de ectoparásitos (76,7 \%) en su domicilio (Tabla 2).

\section{Enfermedad}

Al estudiar y comparar los títulos de los anticuerpos se encontró que seis $(16,6 \%)$ de los pacientes con síndrome febril positivos por IFI, presentaron seroconversión o serorefuerzo con un alza cuádruple de anticuerpos entre la muestra de la fase convaleciente $y$ fase aguda. El título más alto encontrado en ellos fue de 128 en la muestra de la fase aguda, $y$ de 512 en la muestra de la fase convaleciente (Tabla 3 ).

\section{DISCUSIÓN}

El presente estudio reveló una seropositividad del 40,4\% en pacientes febriles no maláricos, una frecuencia de infección previa por rickettsias del 33,7 \% y rickettsiosis en seis de estos pacientes, provenientes de los municipios de Apartadó, Chigorodó, Necoclí y Turbo. Lo anterior permite evidenciar que la infección y la enfermedad por rickettsias del GFM continúa presentándose en zonas como el Urabá antioqueño, además de no estar limitada únicamente a los municipios de Turbo y Necoclí, donde se han realizado reportes en años anteriores $(9,11)$.

En cuanto al reporte de FMMR en Latinoamérica, Brasil es el país con el mayor número de casos registrados, entre 1995 y 2004 hubo 334 casos confirmados, con una mortalidad del 31 \% (23). El Salvador, Honduras y Nicaragua han demostrado evidencia serológica de infección humana y/o animal por los grupos de las fiebres manchadas, con cifras que varían según la endemicidad del área, pero que han permitido identificar zonas de circulación de rickettsias del GFM con metodología similar a la aplicada en nuestro estudio $(6,24)$. Estos datos nos muestran una mayor seropositividad comparada con trabajos previos en la región, como es el caso del estudio de Quintero et aI. (2013), donde se encontró una seropositividad del $24 \%$ en pacientes provenientes de los municipios de Apartadó, Necoclí y Turbo (25); y similar a la encontrada por Padmanabha et aI. (2008), 
Tabla 2. Porcentaje de los participantes seropositivos según las variables sociodemográficas

\begin{tabular}{|c|c|c|c|}
\hline Variable & & $\mathrm{n}=30^{*}$ & $\%$ \\
\hline \multirow[t]{2}{*}{ Sexo } & Femenino & 9 & 30,0 \\
\hline & Masculino & 21 & 70,0 \\
\hline \multirow[t]{3}{*}{ Grupos de edad } & 15 a 26 & 14 & 46,7 \\
\hline & 27 a 59 & 12 & 40,0 \\
\hline & Mayores de 60 & 4 & 13,3 \\
\hline \multirow[t]{3}{*}{ Municipio de origen } & Apartadó & 10 & 33,3 \\
\hline & Necoclí & 10 & 33,3 \\
\hline & Turbo & 10 & 33,3 \\
\hline \multirow[t]{2}{*}{ Raza } & Afroamericana & 3 & 10,0 \\
\hline & Mestiza & 25 & 83,3 \\
\hline \multirow[t]{2}{*}{ Zona } & Urbana & 11 & 36,7 \\
\hline & Rural & 18 & 60,0 \\
\hline \multirow[t]{2}{*}{ Ocupación } & En interiores & 21 & 70,0 \\
\hline & En exteriores & 7 & 23,3 \\
\hline \multirow[t]{2}{*}{ Animales domésticos } & Sí & 19 & 63,3 \\
\hline & No & 9 & 30,0 \\
\hline \multirow[t]{2}{*}{ Contacto con ectoparásitos } & Sí & 23 & 76,7 \\
\hline & No & 5 & 16,7 \\
\hline \multirow[t]{2}{*}{ Agua potable } & Sí & 4 & 13,3 \\
\hline & No & 24 & 80,0 \\
\hline \multirow[t]{2}{*}{ Recolección basuras } & Sí & 12 & 40,0 \\
\hline & No & 16 & 53,3 \\
\hline \multirow[t]{2}{*}{ Acueducto y alcantarillado } & Sí & 12 & 40,0 \\
\hline & No & 16 & 53,3 \\
\hline
\end{tabular}

*Hubo pérdida de datos

Tabla 3. Principales aspectos sociodemográficos y clínicos de los pacientes con seroconversión o serorefuerzos

\begin{tabular}{|c|c|c|c|c|c|c|c|c|c|c|}
\hline Código & $\begin{array}{c}\text { Dilución } \\
\text { M1 }\end{array}$ & $\begin{array}{c}\text { Dilución } \\
\text { M2 }\end{array}$ & Municipio & Sexo & $\begin{array}{c}\text { Edad } \\
\text { (años) }\end{array}$ & Ocupación & Zona & $\begin{array}{l}\text { Animales } \\
\text { domésticos }\end{array}$ & $\begin{array}{c}\text { Plaquetas } \\
\text { (mm3) }\end{array}$ & Petequias \\
\hline 6 & - & $1 / 128^{*}$ & Apartadó & $M$ & 42 & Oficios varios & Rural & No reporta & 195.000 & No \\
\hline 13 & - & $1 / 256$ & Necoclí & $\mathrm{F}$ & 9 & Estudiante & Rural & $\begin{array}{c}\text { Perro, gallina, } \\
\text { pato }\end{array}$ & 97.000 & No \\
\hline 37 & $1 / 128$ & $1 / 512$ & Chigorodó & M & 36 & Obrero & Urbana & No reporta & 65.000 & No \\
\hline 43 & - & $1 / 128^{*}$ & Necoclí & $M$ & 18 & Estudiante & Rural & Perro, gato & 109.000 & No \\
\hline 54 & - & $1 / 256$ & Turbo & $\mathrm{F}$ & 38 & $\begin{array}{l}\text { Auxiliar de } \\
\text { enfermería }\end{array}$ & Rural & Perro & 60.000 & Sí \\
\hline 67 & - & $1 / 128^{*}$ & Apartadó & $\mathrm{F}$ & 76 & Ama de casa & Rural & Perro & 270.000 & No \\
\hline
\end{tabular}

M1= Fase aguda, M2= Fase convaleciente, F= Femenino, M= Masculino. *M2 (muestra en fase convaleciente) $128 \rightarrow$ se tamizó M1 (muestra en fase aguda) en dilución 1:32.

donde se obtuvo una prevalencia del 29,2 \% en una muestra de 642 personas de Necoclí (26). Las diferencias observadas podrían ser explicadas por la desigualdad en los diseños metodológicos, el tipo de muestreo y los períodos de reclutamiento de los pacientes en cada uno de los estudios. 
En cuanto a los títulos de los anticuerpos encontrados en los pacientes con la enfermedad, se detectó que fueron bajos, en contraste con la sintomatología presentada y con lo reportado en el trabajo realizado por Quintero et al. (2013) en esta zona del Urabá, donde se observó una reactividad hasta una dilución de 1:131072 en dos de los pacientes sintomáticos de Turbo (25). Los títulos más bajos en el presente estudio pueden deberse a que los pacientes hayan sido infectados por otras especies de rickettsias menos virulentas tales como $R$. felis o $R$. parkeri (27). El estudio de Londoño et al. en la región reportó Rickettsia sp. cepa Atlantic rainforest, la cual es considerada como una cepa de $R$. parkeri, vinculada como agente causal de una rickettsiosis con sintomatología menos grave que la FMMR en Brasil (28). La circulación de esta Rickettsia en la zona puede sugerir que la población en esta región podría estar expuesta a sufrir una enfermedad menos sintomática que pudiera estar pasando desapercibida y subdiagnosticada.

Aunque el ensayo de IFI es el método de referencia para el diagnóstico de rickettsiosis, presenta limitaciones debido a la reacción cruzada que existe entre las diferentes especies del género Rickettsia, por lo cual, estos títulos y la severidad de los síntomas pudieron ser debidos a otras especies diferentes a $R$. rickettsii $(21,22)$. De acuerdo con lo anterior, para futuros estudios se sugiere explorar los resultados obtenidos con otras especies de Rickettsia a través de IFI, con el fin de identificar el antígeno más probablemente involucrado en una reacción homóloga, identificado por inmunoprecipitación o por otras técnicas alternas.

Reportes recientes de casos de rickettsiosis en Antioquia (14) y Meta (15), indican que la infección por diferentes especies de rickettsias es un evento que se ha estado presentando en diferentes lugares del país, $y$ que el panorama continúa siendo desconocido para el personal de la salud.

Lo anterior, sumado al hecho de que no se cuenta con un diagnóstico en fase aguda y no se puede confiar en la diferenciación clínica, implica un gran impacto en la salud pública por el riesgo potencial de muerte o secuelas permanentes para la población de estas zonas.

Entre las manifestaciones clínicas que presentaron los pacientes con la enfermedad se incluyó la fiebre (temperatura mayor a $38^{\circ} \mathrm{C}$ ), cefalea, malestar general, mialgias, artralgias, vómito y dolor abdominal, entre otras; las cuales han sido también reportadas en casos de otros países latinoamericanos como México, Costa Rica, Panamá, Brasil y Argentina (29-32). Estas manifestaciones son compartidas con otras entidades infecciosas que se presentan en la zona, tales como el dengue y Leptospira.

Aunque las rickettsiosis no tienen signos patognomónicos, existen síntomas sugestivos como presencia de fiebre, erupción cutánea, linfadenopatía y escaras de inoculación (33). Otro hallazgo común en esta enfermedad son las alteraciones hematológicas como la trombocitopenia. Esta podría deberse en parte a la afinidad de la bacteria por las células endoteliales, lo que generaría un desgaste de las plaquetas al ser estimuladas dentro de la vía de la coagulación en un esfuerzo por contrarrestar el daño generado por las bacterias.

Vale recordar que dicha trombocitopenia se logró observar en cuatro de los pacientes que presentaron la enfermedad (34). No en todos los casos de rickettsiosis se van a presentar estos sionos y síntomas, por lo tanto, la rickettsiosis se debe incluir como diagnóstico diferencial en los síndromes febriles en la región.

Un 63,3 \% de los pacientes seropositivos para Rickettsia spp., reportaron contacto con animales domésticos tales como perros y equinos, los cuales previamente han sido vinculados como centinelas de la infección en la zona, por ejemplo, en el trabajo de Quintero et al. (2017), se mostró seropositividad de Ios animales domésticos y la asociación con un indicador del estado serológico de los humanos, donde muestran una seropositividad en humanos de 3,1 veces mayor en las zonas donde los animales tenían una seropositividad mayor del $40 \%$, comparada con las zonas donde la seropositividad era menor del $20 \%$ (35). De esta forma, se evidencia la importancia de estudiar la seropositividad en los animales domésticos en estudios futuros, los cuales se comportan como centinelas de la enfermedad y hacen parte del ciclo de vida de la garrapata $(36,37)$.

Finalmente, aunque todos los pacientes seropositivos manifestaron ver ectoparásitos en sus viviendas, esta variable no fue útil, ya que no se discriminaron. En caso de haberse diferenciado, sería de importancia verificar la presencia y tipo de garrapatas, ya que estas se incluyen dentro de los principales vectores de la bacteria para cumplir funciones de reservorio $y$ vector, claves para la diseminación de la infección (4).

\section{CONCLUSIONES}

Los síndromes febriles causados por rickettsias, en especial por $R$. rickettsii, son enfermedades severas que pueden llegar a ser letales. Sin embargo, si se da el 
tratamiento oportuno (doxiciclina), se puede prevenir este tipo de consecuencias. De aquí la importancia de poder diagnosticar las rickettsias de forma adecuada $y$ oportuna. Además, los hallazgos de este estudio confirman la importancia de Rickettsia del GFM en la región del Urabá antioqueño como causante de la infección y como uno de los agentes relacionados con el síndrome febril en este lugar, dada la baja especificidad de las manifestaciones clínicas de los síndromes febriles, la dificultad para el diagnóstico y el poco conocimiento que tiene el personal médico, acerca de las rickettsiosis. En consecuencia, se hace evidente la necesidad de mejorar la disponibilidad y oportunidad de los recursos para su diagnóstico diferencial, con el fin de aportar a las medidas de control y prevención en la zona, ya que es muy probable que esta infección esté siendo subdiagnosticada.

De igual forma, se hace mandatorio instaurar el tratamiento inmediato, en casos compatibles (sospechosos), para evitar consecuencias trágicas (tales como la muerte o las secuelas permanentes), ocasionadas por infecciones para las que existe una terapia efectiva.

\section{CONFLICTOS DE INTERESES}

Ninguno por declarar.

\section{REFERENCIAS BIBLIOGRÁFICAS}

1. Gillespie JJ, Williams K, Shukla M, Snyder EE, Nordberg EK, Ceraul SM, et al. Rickettsia phylogenomics: unwinding the intricacies of obligate intracellular life. PLoS One. 2008;3(4): e2018. DOI 10.1371/journal.pone.0002018.

2. Gómez Sánchez MM, Gómez Sánchez MC. Rickettsiosis: fiebre botonosa mediterránea. Medicina Integral. 2001;38(3):110-15.

3. Sahni SK, Narra HP, Sahni A, Walker DH. Recent molecular insights into rickettsial pathogenesis and immunity. Future Microbiol. 2013;8(10):1265-88. DOI 10.2217/fmb.13.102.

4. Szabó PJ, Pinter A, Labruna, MB. Ecology, biology and distribution of spotted-fever tick vectors in Brazil. Front Cell Infect Microbiol. 2013;3,(27). DOI 10.3389/fcimb.2013.00027.

5. Parola P, Labruna MB, Raoult D. Tick-borne rickettsioses in America: Unanswered questions and emerging diseases. Curr Infect Dis Rep. 2009;11(1):40-50. DOI 10.1007/s1 1908-009-0007-5.
6. Álvarez Hernández G, Candia Plata MC, Bolado Martínez E, Delgado de la Mora J, Soto Guzmán A, López Soto LF. Fiebre manchada por Rickettsia rickettsii en las Américas: un problema creciente de salud pública. Rev Unir Ind Santander Salud. 2015;47(3):24359. DOI 10.18273/revsal.v47n3-2015001.

7. Dantas Torres F. Rocky Mountain spotted fever. Lancet Infect Dis. 2007;7(11):724-32. DOI 10.1016/S14733099(07)70261-X.

8. Patiño Camargo L. Fiebre manchada en Tobia, Colombia. Biomedica. 2006;26(2):178-93.

9. Acosta J, Urquijo L, Díaz A, Sepúlveda M, Mantilla G, Heredia D, et al. Brote de rickettsiosis en Necoclí, Antioquia. IQEN. 2006;11(12):177-86.

10. Hidaloo M, Lizarazo D, Ovalle MV, Castañeda E, Heredia D, Zambrano P, et al. Brote de rickettsiosis en Los Córdobas, departamento de Córdoba. IQEN. 2007; 12(24):371-78.

11. Pacheco O, Giraldo R, Martínez M, Hidalgo M, Galeano A, Echeverri I, et al. Estudio de brote febril hemorrágico en el corregimiento de Alto de Mulatos - Distrito Especial Portuario de Turbo, Antioquia. IQEN. 2008;13(10):145-60.

12. Miranda AM, Flórez S, Mattar S. Alta seroprevalencia de rickettsiosis en trabajadores del campo en el municipio de Ciénaga de Oro, Córdoba. IQEN. 2002; 7:72-5.

13. Hidalgo M, Orejuela L, Fuya P, Carrillo P, Hernández J, Parra E, et al. Rocky Mountain Spotted Fever, Colombia. Emerg Infect Dis. 2007;13(7):1058-60. DOI 10.3201/eid1307.060537.

14. Acevedo LY, Londoño A, Paternina L, Montes C, Pájaro D, Jaramillo K, et al. Descripción de un nuevo foco de fiebre manchada de las montañas rocosas en el municipio de Uramita, departamento de Antioquia, Colombia. Rev Biomed. 2015;26(1):113-14.

15. Gómez Quintero CH, Faccini Martínez AA, Botero García CA, Lozano M, Sánchez Lerma L, Miranda J, et al. Probable case of spotted fever group rickettsial infection in a new-suspected endemic area, Colombia. J Infect Public Health. 2017;10(3):353-56. DOI 10.1016/j.jiph.2016.08.012.

16. Colombia. Ministerio de Salud y Protección Social, Organización Panamericana de la Salud. Propuesta de abordaje sindrómico de zoonosis con potencial epidémico [internet]. [consultado 2017 oct 06]. 2012. Disponible en: https://bit.ly/2XbuiT9

17. Newhouse VF, Shepard CC, Redus MD, Tzianabos T, McDade JE. A comparison of the complement fixation, 
indirect fluorescent antibody, and microagglutination tests for the serological diagnosis of rickettsial diseases. Am J Trop Med Hyg. 1979;28(2):387-95.

18. Clements ML, Dumler JS, Fiset P, Wissemant CL Jr, Snyder MJ, Levine MM. Serodiagnosis of Rocky Mountain spotted fever: comparison of IgM and IgG enzyme-linked immunosorbent assays and indirect fluorescent antibody test. J Infect Dis. 1983;148(5):876-80.

19. Philip RN, Casper EA, MacCormack JN, Sexton D, Thomas LA, Anacker RL, et al. A comparison of serologic methods for diagnosis of Rocky Mountain spotted fever. Am J Epidemiol, 1977;105(1):56-67.

20. Londoño AF, Acevedo LY, Marín D, Contreras V, Díaz FJ, Valbuena G, et al. Human prevalence of the spotted fever group (SFG) rickettsiae in endemic zones of Northwestern Colombia. Ticks Tick-borne Dis. 2017; 8(4):477-82. DOI 10.1016/j.ttbdis.2017.02.006.

21. Oteo JA, Nava S, Sousa R, Mattar S, Venzal JM, Abarca $\mathrm{K}$, et al. Guías Latinoamericanas de la RIICER para el diagnóstico de las rickettsiosis transmitidas por garrapatas. Rev Chilena Infectol. 2014;31(1):54-65. DOI org/10.4067/S0716-10182014000100009.

22. Portillo A, de Sousa R, Santibanez S, Duarte A, Edouard S, Fonseca, et al. Guidelines for the Detection of Rickettsia spp. Vector Borne Zoonotic Dis. 2017;17(1):2332. DOI 10.1089/vbz.2016.1966.

23. Díaz JS, Cataño JC. Fiebre manchada de las montañas rocosas: ni tan manchada ni tan montañosa como pensábamos. Infect. 2010;14(4):264-76. DOI 10.1016/ S0123-9392(10)70120-X.

24. Labruna MB, Mattar S, Navas S, Bermudez S, Venzal JM, Dols G, et al. Rickettsiosis en América Latina, el Caribe, España y Portugal. Rev.MVZ Córdoba. 2011;16(2):2435-57.

25. Quintero Vélez JC, Londoño AF, Díaz FJ, Agudelo Flórez P, Arboleda M, Rodas JD. Ecoepidemiología de la infección por rickettsias en roedores, ectoparásitos y humanos en el noroeste de Antioquia, Colombia. Biomédica. 2013;33(1):38-51. DOI 10.7705/biomedica. $833 i 0.735$.

26. Padmanabha H, Hidalgo M, Valbuena G, Castañeda E, Galeano A, Puerta H, et al. Geographic variation in risk factors for SFG rickettsial and leptospiral exposure in Colombia. Vector Borne Zoonotic Dis. 2009;9(5):483-90. DOI 10.1089/vbz.2008.0092.

27. Arroyave E, Londoño AF, Quintero JC, Agudelo Flórez p, Arboleda M, Díaz FJ, et al. Etiología y caracterización epidemiológica del síndrome febril no palúdico en tres municipios del Urabá antioqueño, Colombia. Biomedica. 2013;33(1):99-107. DOI 10.7705/biomedica. $\nabla 33 i 0.734$.

28. Londoño AF, Acevedo LY, Marín D, Contreras V, Díaz FJ, Valbuena G, et al. Wild and domestic animals likely involved in rickettsial endemic zones of Northwestern Colombia. Ticks Tick Borne Dis. 2017;8(6):887-94. DOI 10.1016/j.ttbdis.2017.07.007.

29. Arguello AP, Hun L, Rivera P, Taylor L. A fatal urban case of Rocky Mountain spotted fever presenting an eschar in San Jose, Costa Rica. Am J Trop Med Hyg. 2012; 87(2):345-8. DOI 10.4269/ajtmh.2012.12-0153.

30. Estripeaut D, Aramburu MG, Saez-Llorens X, Thompson HA, Dasch GA, Paddock CD, et al. Rocky Mountain spotted fever, Panama. Emerg Infect Dis. 2007;13(11):1763-65. DOI 10.3201/eid1311.070931.

31. Pinter A, França AC, de Souza CE, Sabbo C, Mendes do Nascimento EM, Fabiana Pereira dos Santos C, et al. Febre maculosa brasileira. BEPA. 2011;8(1):3-31.

32. Paddock CD, Fernandez S, Echenique GA, Sumner JW, Reeves WK, Zaki SR, et al. Rocky Mountain spotted fever in Argentina. Am J Trop Med Hyg. 2008;78(4):687-92.

33. Hidalgo M, Faccini Martínez AA, Valbuena G. Rickettsiosis transmitidas por garrapatas en las Américas: avances clínicos y epidemiológicos, y retos en el diagnóstico. Biomedica. 2013;33(1):161-78. DOI 10.7705/biomedica. $833 i 0.1466$.

34. Abarca K, Oteo JA. Aproximación clínica y principales rickettsiosis transmitidas por garrapatas presentes en Latinoamérica. Rev. chil. infectol. 2014;31(5):56976. DOI 10.4067/S0716-10182014000500009.

35. Quintero Vélez JC, Paternina LE, Uribe A, Muskus C, Hidalgo M, Gil J, et al. Eco-epidemiological analysis of rickettsial seropositivity in rural areas of Colombia: A multilevel approach. PLoS Negl Trop Dis. 2017; 11(9):e0005892. DOI 10.1371/journal.pntd.0005892.

36. Pinter A, Horta MC, Pacheco RC, Moraes-Filho J, Labruna MB. Serosurvey of Rickettsia spp. in dogs and humans from an endemic area for Brazilian spotted fever in the State of São Paulo, Brazil. Cad Saude Publica. 2008; 24(2):247-52. DOI 10.1590/S0102-311X200800020000.

37. Sangioni LA, Horta MC, Vianna MC, Gennari SM, Soares RM, Labruna MB, et al. Rickettsial Infection in Animals and Brazilian Spotted Fever Endemicity. Emerg Infect Dis. 2005;11(2):265-70. DOI 10.3201/eid1 102.040656. 